\title{
Subjecció i revolta en el segle de la Nova Planta
}

\section{René Merle}

\section{(2) OpenEdition}

Journals

Édition électronique

URL : https://journals.openedition.org/ahrf/8873

DOI : 10.4000/ahrf.8873

ISSN : 1952-403X

Éditeur :

Armand Colin, Société des études robespierristes

Édition imprimée

Date de publication : 1 mars 2007

Pagination : 213-216

ISSN : 0003-4436

\section{Référence électronique}

René Merle, « Subjecció i revolta en el segle de la Nova Planta », Annales historiques de la Révolution française [En ligne], 347 | janvier-mars 2007, mis en ligne le 21 juillet 2008, consulté le 24 avril 2022. URL : http://journals.openedition.org/ahrf/8873 ; DOI : https://doi.org/10.4000/ahrf.8873

Ce document a été généré automatiquement le 24 avril 2022.

Tous droits réservés 


\title{
Subjecció i revolta en el segle de la Nova Planta
}

\author{
René Merle
}

\section{RÉFÉRENCE}

Lluís Roura i Aulinas, Subjecció i revolta en el segle de la Nova Planta, Vic, Eumo Editorial, 2006, 292 p., ISBN 84-9766-177-X, $22 €$.

1 Conflit international, la Guerre de Succession fut aussi un conflit interne à la monarchie espagnole. La défaite des Catalans pro-Autrichiens a pour conséquences, avec le décret de « la Nova Planta » (1716), la perte de souveraineté et la suppression des institutions catalanes. Directement placée sous le pouvoir absolutiste des Bourbon et de son représentant, le Capitaine Général, la Catalogne se voit imposer un nouveau système institutionnel et fiscal, appuyé par un très important déploiement militaire.

2 Les décennies qui suivront, jusqu'aux deux conflits avec la France révolutionnaire puis impériale, ont longtemps été présentés, pour la Catalogne, comme une période de tranquillité politique, de forte croissance démographique, de rapide développement économique lié à l'intégration au marché national espagnol et, donc, d'acceptation par les Catalans de l'œuvre modernisatrice et intégratrice de la monarchie absolutiste. Nourri de l'historiographie contemporaine, d'une recherche personnelle poussée et de documents inédits, le très pertinent ouvrage de Lluís Roura i Aulinas offre une tout autre perspective.

3 Tout au long du siècle, en effet, du côté du pouvoir, dans la continuité renforcée du déploiement militaire dans le Principat, persiste une attitude d'extrême défiance vis-àvis d'un peuple supposé intrinsèquement et potentiellement rebelle. L'a priori ne semble cependant pas justifié par l'attitude de la «tranquille » société catalane, sinon par quelques poussées de protestation, rangées par beaucoup du côté d'une histoire purement anecdotique. C'est justement en étudiant de façon approfondie ces accès exceptionnels de conflictualité ouverte que Lluís Roura pointe, au-delà des apparences 
de "tranquillité », la continuité d'attitudes multiformes de résistance dans des secteurs fort divers de la société catalane, sans voir dans ces mouvements une proclamation clairement et politiquement catalaniste. Dans le quart de siècle qui suit 1716, et particulièrement dans les troubles sociaux des premières années 1730 , en dépit du retour des exilés et d'une poussée de pamphlets politiques, les motivations populaires ont bien peu de rapport avec ces ultimes sursauts des engagements passés. L'histoire a tranché.

4 Pour autant, et tout particulièrement dans les conflits qui vont s'aiguiser à partir des années 1740 , l'exaspération populaire est inséparable du sentiment que les mesures contre lesquelles on proteste violent ce que garantissaient les antiques constitutions de Catalogne. Et le seul souvenir, latent ou déclaré, d'institutions abolies depuis 1716, suffit à donner un caractère subversif à des doléances pragmatiques.

5 Les causes de ces agitations populaires sont facilement repérables. L'exaspération sociale procède fondamentalement de la présence des troupes: leur attitude, la nécessité de les loger, et partant l'alourdissement de la fiscalité. Cette militarisation du pays étant la clé de voûte de la mainmise absolutiste sur le Principat, on conçoit quel lien implicite unit cette exaspération sociale à une exaspération politique latente.

6 Cette exaspération s'accroît encore dans la résistance au recrutement: ainsi des troubles de Cervera en 1742-1743, d'autant plus emblématiques qu'ils embrasent une cité historiquement "philippiste », de ceux de Mataró et Lleida dans les années 1750. Ainsi des troubles des années 1760 , années de crise agraire généralisée dans tout le royaume. Ainsi surtout de la très emblématique émeute de 1773 à Barcelone contre les levées de classes et le remplacement, émeute dont les répercussions sont considérables dans tout le Principat.

7 Ainsi encore, dans les années 1780, années de reflux économique et de claire conflictualité, les "révoltes du pain», et notamment celles de Barcelone et de nombreuses localités en 1789 : révoltes trop facilement réduites à de simples révoltes de subsistance propres aux sociétés d'Ancien Régime, quand elles ne sont pas mises en rapport avec les événements français. Lluís Roura, au contraire, insiste sur la continuité entre ces émeutes de 1789 et la longue liste des troubles antérieurs.

Ces explosions de conflictualité sont révélatrices d'une profonde volonté de résistance dans la société catalane. Pour autant, les secteurs sociaux divers, et parfois opposés, qui portent cette résistance sont loin de former un vrai front commun, cohérent politiquement et idéologiquement.

Dans les tumultes urbains et tout particulièrement dans les émeutes avec passage à la violence collective, le gros des troupes est recruté dans la plèbe, et notamment celle des apprentis et jeunes journaliers, touchés de plein fouet par l'éclatement des cadres anciens, celle des ménagères exaspérées, plèbe urbaine vite renforcée de paysans du proche terroir.

10 Mais cette levée populaire contre le pouvoir, et au premier chef ses représentants municipaux, trouve des sympathies, des protections, voire des complicités actives dans d'autres milieux, et tout particulièrement dans les représentants et dirigeants des corps de métiers et corporations. Ces protagonistes essentiels de l'évident développement économique catalan, par définition réalistes, inscrivent leurs activités dans le cadre accepté désormais de la monarchie absolue. Ils n'en sont pas moins doublement frustrés, au plan politique comme au plan économique. 
$11 \mathrm{Au}$ plan politique, le mécontentement populaire et artisan permet à ces secteurs d'attaquer le pouvoir local dont ils sont exclus et de revendiquer une participation au gouvernement de la cité. Revendication qui peut s'exercer légalement, mais qui peut aussi (l'action de la Confédération des «Gremis » de Cervera en est un bon exemple) s'appuyer d'une véritable organisation clandestine efficacement « révolutionnaire ». Et au plan économique, ces secteurs sont frustrés quand la politique royale, en exerçant par le recrutement une importante ponction sur la main-d'œuvre, risque de mettre en cause le fragile dynamisme productif et commerçant (en témoigne clairement, lors de la crise de 1773, la supplique de l'autoproclamée Députation de Catalogne).

12 Dans ces conditions, les références aux antiques libertés catalanes sont non seulement l'expression sincère de sentiments viscéraux, mais encore le véhicule de revendications concrètes dans le cadre très présent de l'autoritarisme bourbonien. On ne refuse pas $a$ priori la politique de modernisation et d'uniformisation menée par la monarchie, mais si cette uniformisation ne se fait pas dans la justice et lèse les intérêts de ces groupes sociaux, l'évocation des droits supprimés par le décret de 1716 vient cautionner la protestation.

13 Cette attitude est aussi bien marquée dans l'oligarchie catalane, marginalisée par le renforcement de l'absolutisme. Certes, elle demeure tout au long du siècle marquée par le résultat de la Guerre de Succession, mais bientôt cette guerre ne sera guère plus pour elle qu'une référence. L'oligarchie catalane, seule couche sociale à même de formuler des aspirations politiques, ne demande pas le retour au passé institutionnel, et encore moins dynastique. Elle refuse d'autant moins les critères d'efficacité et de rationalisation dont se justifie l'absolutisme que nombre de ces oligarques, hommes des Lumières, en sont partisans. Mais elle essaie, en compensation ponctuelle, de faire aboutir quelques-uns de ses intérêts particuliers dans le cadre de la monarchie absolue, en se référant à la spécificité historique du pays.

14 D'où les ambiguïtés de ses comportements, oscillant entre une menaçante nostalgie catalaniste et la solennelle proclamation d'allégeance. Les grandes célébrations officielles en l'honneur des monarques, et l'imposant concours populaire qui les accompagne, sont pour cette oligarchie, à la fois preuve de leur fidélité et de leur intégration, et manière de témoigner de l'ascendant qu'elles exercent et de leurs capacités d'organisation.

15 Ces résistances sont donc résistances d'intérêt et non véritablement de principes. Il n'en reste pas moins que, plus profondément, la conscience de la dimension politique des événements, particulièrement ceux de 1773-1774 se reflète dans le langage : des termes comme "patrie ", "nation » réapparaissent, chargés de sens nouveaux. La meilleure preuve de l'importance de ces résistances est l'attention que leur prête la monarchie, tant elles révèlent la fragilité de l'apogée absolutiste. Tout au long du siècle, la monarchie ne déviera pas dans sa volonté d'imposer son pouvoir absolu, et la modernisation et réorganisation administrative, fiscale, militaire, de ce pouvoir.

Mais en fonction des résistances, la monarchie peut apparemment lâcher du lest. Ainsi de la création de la Junte générale des Collèges et " Gremis » de Barcelone, en 1745, et sa convocation pour lui confier le rétablissement de l'ordre dans les crises de 1766, 1773 et 1789. Ainsi de la création de la Junte de gouvernement de Catalogne en 1775. Mais ces institutions concédées ne font en fait que renforcer la « Nova Planta ». 
17 Un des signes les plus évidents de l'embarras de la monarchie devant les résistances est sa politique militaire. Comment concilier la méfiance devant un armement des Catalans, qui perdure jusqu'aux années 1760 , avec le désir manifesté ensuite d'inclure les Catalans dans l'imposition nationale du service militaire, que la supposée intégration des Catalans semble rendre possible? L'échec sera au terme des deux entreprises, sujétion et intégration...

18 Tranquille XVIII ${ }^{\mathrm{e}}$ siècle ? La très riche étude de Lluís Roura souligne au contraire quelle dynamique révolutionnaire bouillonne dans les paramètres de la révolte traditionnelle. Le conflit avec la France, initié en 1793, va brouiller les cartes. Le pouvoir s'emploiera, avec succès, à orienter cette potentielle énergie révolutionnaire contre l'ennemi extérieur. En quelques pages finales qui s'élargissent aux événements de Valence et des Baléares, Lluís Roura débouche de façon stimulante sur le complexe chantier ouvert de la crise de la monarchie à la charnière des deux siècles. 